\title{
TITLE:
}

\section{Coincidental intraguild predation by caterpillars on spider mites.}

$\operatorname{AUTHOR}(\mathrm{S})$ :

Shirotsuka, Kanako; Yano, Shuichi

\section{CITATION:}

Shirotsuka, Kanako ... [et al]. Coincidental intraguild predation by caterpillars on spider mites.. Experimental \& applied acarology 2012, 56(4): 355-564

\section{ISSUE DATE:}

2012-01-29

URL:

http://hdl.handle.net/2433/154871

\section{RIGHT:}

The final publication is available at www.springerlink.com; This is not the published version. Please cite only the published version.; この論文 は出版社版でありません。引用の際には出版社版をご確認ご利用くだ さい。 


\title{
Coincidental intraguild predation by caterpillars on spider mites
}

\author{
Shirotsuka Kanako and Yano Shuichi \\ Laboratory of Ecological Information Department of Agriculture Kyoto \\ University Sakyo-ku, Kyoto, 606-8502, Japan \\ Laboratory of Ecological Information
}

Graduate School of Agriculture Kyoto University Sakyo-ku, Kyoto, 606-8502, Japan

Laboratory of Ecological Information

$+81-75-753-6135$

$+81-75-753-6135$

kshiro@kais.kyoto-u.ac.jp

\section{Abstract}

Intraguild predation (IGP) is defined as the killing and eating of prey species by a predator that also can utilize the resources of the prey. It is mainly reported among carnivores that share common herbivorous prey. However, a large chewing herbivore could prey upon sedentary and/or micro herbivores in addition to utilizing a host plant. To investigate such coincidental IGP, we observed the behavioral responses of the polyphagous mite Tetranychus kanzawai Kishida (Acari: Tetranychidae) when its host plant Cayratia japonica (Thunb.) Gagnep. (Vitaceae) was attacked by hornworms, Theretra japonica Boisduval (Sphingidae) and T. oldenlandiae Fabricius (Sphingidae). We also examined an interaction between the oligophagous mite Panonychus citri McGregor (Acari: Tetranychidae) and caterpillars of the swallowtail Papilio xuthus L. (Papilionidae) that share citrus plants as their main food source. Although all T. kanzawai and some active stage $P$. citri tried to escape from the coincidental IGP, some were consumed together with eggs, quiescent mites, and host plant leaves, suggesting that coincidental IGP occurs on spider mites in the wild. Moreover, neither hornworms nor swallowtail caterpillars distinguished between spider miteinfested and uninfested leaves, suggesting that the mite-infested leaves do not discourage caterpillar feeding. The reasons that the mites have no effective defense against coincidental IGP other than escaping are discussed. 
Keywords: coincidental intraguild predation; herbivorous; hornworm; swallowtail; Tetranychus kanzawai; Panonychus citri

\section{Introduction}

Intraguild predation (IGP), the killing and eating of prey species by a predator that also can utilize the resources of the prey (Polis et al. 1989), is reported among predators that share common herbivorous prey, as well as among omnivores and herbivores that share common plant resources (e.g., Pallini et al. 1998; Montserrat 2008). Growing evidence indicates the importance of IGP among predators in many natural communities (Holt and Polis 1997; Roda et al. 2001; Kaneko 2007). As numerous herbivore species with a variety of feeding modes coexist on the same plant species (Strong et al. 1984), a large chewing herbivore may accidentally prey upon resident and/or micro-herbivores together with host plant tissues. Polis et al. (1989) defined this type of intraguild predation as 'coincidental IGP.' Langellotto et al. (2006) reported coincidental IGP among parasitoids in which ectoparasitoids consume host insects that have been previously parasitized by endoparasitoids. Although coincidental IGP seems to be widespread (Janzen, 1977; Polis et al., 1989), no study has ever examined coincidental IGP on spider mites by large herbivores that exclusively feed on plants.

As some predators have developed effective defenses against IGP (e.g., Faraji et al. 2000; Roda et al. 2001), prey species among herbivores may also have behavioral or other means of adaptation to avoid coincidental IGP by chewing herbivores when the herbivores impose serious selection pressure on the prey.

The polyphagous spider mite Tetranychus kanzawai Kishida (Acari: Tetranychidae) feeds on Cayratia japonica (Thumb.) Gagnep (Vitaceae) (Oku and Yano 2007; Ozawa et al. 2009). The plant is also infested by the hornworms Theretra japonica Boisduval (Sphingidae) and Theretra oldenlandiae Fabricius (Sphingidae) (Mutuura et al. 1965). The final instar hornworm consumes more than $20 \mathrm{C}$. japonica leaves ( $8 \mathrm{~cm}$ in length, $4 \mathrm{~cm}$ in width) in $24 \mathrm{~h}$, and often exhausts individual C. japonica plants (Shirotsuka, personal observation). Therefore, the hornworms may accidentally prey upon spider mites together with C. japonica leaves. Moreover, a hornworm exhausts one T. kanzawai colony on 
C. japonica within a few minutes whereas native predatory mites such as Neoseiulus womersleyi Schicha (Acari: Phytoseiidae) can take several days to accomplish this. Therefore, hornworms may impose selection pressure on $T$. kanzawai in the same way as predatory mites, and hence the mite may also have some countermeasure to avoid coincidental IGP by the hornworms. We also observed the interactions between the citrus red mite Panonychus citri McGregor (Acari: Tetracychidae) and the swallowtail butterfly, Papilio xuthus L. (Papilionidae), which share citrus plants as their main food. Compared to $T$. kanzawai, P. citri should frequently encounter herbivorous guild members; hence, the interactions over coincidental IGP on the plants should be more conspicuous.

Thus, by examining the IGP on both polyphagous and oligophagous spider mites by caterpillars, we intended to examine the generality of coincidental IGP and possible countermeasure against it in this system.

\section{Materials and Methods}

\section{Plants}

Cayratia japonica is a perennial vine commonly found around agricultural fields and shrubs from the tropical to the template zones in Asia (Makino 1982)that is often infested by the herbivorous mite Tetranychus kanzawai (Oku and Yano 2007; Ozawa and Yano. 2009). The leaves are pedately compound with each leaf consisting of five leaflets (Satake et al. 1982). All C. japonica leaves used in the following experiments were obtained from the campus of Kyoto University.

Poncirus trifoliata L. (Raf.) is a deciduous citrus shrub. The leaves are compound with each leaf consisting of three leaflets (Satake et al. 1989). This species is often used for hedging in Japan.

\section{Caterpillars}

The hornworms, Theretra japonica and T. oldenlandiae feed on Vitaceae plants from June to October in Japan (Mutuura et al. 1965). We collected the eggs and larvae of both hornworms from $C$. japonica and reared them on $C$. japonica leaves. The first to fourth instars were individually reared in 200-ml transparent 
cups with air holes, while the fifth instars were individually reared in 900-ml cups. The cups were maintained at $25^{\circ} \mathrm{C}, 50 \%$ relative humidity, and L16/D18 photoperiod (hereafter laboratory conditions).

Papilio xuthus feeds on citrus plants from March to October in Japan (Fukuda et al. 1982). We collected eggs and larvae of $P$. xuthus from $P$. trifoliata and reared them on P. trifoliata leaves under laboratory conditions. The first to fourth instars were individually reared in $200 \mathrm{ml}$ plastic transparent cups, and the fifth instars were reared in $900 \mathrm{ml}$ cups.

\section{Mites}

Tetranychus kanzawai is a polyphagous mite that infests various wild and cultivated plants (e.g. Gomi and Gotoh 1996). We used two T. kanzawai populations (wild and laboratory populations) collected from C. japonica in Kyoto, Japan. The wild strain was collected as needed in 2010 and temporarily maintained on $C$. japonica leaves under laboratory conditions prior to the following experiments. The laboratory strain had been maintained on expanded leaves of the kidney bean Phaseolus vulgaris $L$. and pressed onto water-saturated cotton in Petri dishes (90 mm diameter, $14 \mathrm{~mm}$ depth; hereafter bean leaf discs) under laboratory conditions since 2000.

Panonychus citri is a serious citrus pest of citrus plants (e.g., Shinkaji 1979). The study population of $P$. citri was collected from $P$. trifoliata and maintained on bean leaf discs in the manner described above.

The approximate body length of an adult female mite is $<0.5 \mathrm{~mm}$, while that of fifth instar caterpillars is $80 \mathrm{~mm}$ (hornworms) and $40 \mathrm{~mm}$ (P. xuthus).

\section{Coincidental IGP on polyphagous mites: Kanzawa spider mites preyed upon by hornworms}

\section{Behavioral avoidance of T. kanzawai against hornworm feeding}

To observe the behavioral responses of T. kanzawai when attacked by hornworms, we collected $C$. japonica leaves infested by T. kanzawai (wild strain) and inserted them individually into a 2-ml tube bottle filled with water until the subsequent experiment. We also introduced three mated T. kanzawai females 
(laboratory strain) onto each uninfested $C$. japonica leaf prepared in the same manner and maintained them under laboratory conditions. After 10 days, $T$. kanzawai individuals of all developmental stages were present on each leaf. We then presented the infested $C$. japonica leaves to a fifth instar hornworm $(T$. japonica and T. oldenlandiae). We continuously observed caterpillars using stereomicroscopes and scored every contact with all mite stages. Therefore, the number of available observations (see Results) differed among the developmental stages (egg, larva, nymph, adult, quiescent) of the mites. Because observations were made only when caterpillars had vigorously consumed leaves, possible differences in preference among caterpillar individuals were not reflected in the data. Therefore, each encounter was treated as independent data. The data for the active stages (larva, nymph, adult) were subjected to a Wald test (SAS Institute Inc. 1998) to determine the effects of developmental stage and mite strain.

\section{Preference of hornworms for T. kanzawai-infested leaflets}

To determine whether hornworms avoided feeding on T. kanzawai-infested leaves, we conducted dual choice tests. This test was performed to examine whether spider mite-infested leaves may somehow discourage caterpillar feeding. We removed all leaflets except for a single pair of detached $C$. japonica compound leaves, which were inserted into a 2-ml tube bottle filled with water (Fig. 1-a). We then introduced three mated adult female $T$. kanzawai onto one of the leaflets, banded the petiole with wet cotton to prevent the mites from escaping, and maintained the setup under laboratory conditions. After $24 \mathrm{~h}$, when all mites had settled on the introduced leaflet, we removed the cotton and introduced a fifth instar hornworm to the bottom edge of the leaf to observe which leaflet the caterpillar targeted first (Fig. 1-b). This experiment was repeated 24 times using 11 T. japonica caterpillars and 30 times using 29 T. oldenlandiae caterpillars. New leaves and new spider mites were used for every replicate. The data were subjected to a Wilcoxon signed-ranks test to control for possible differences in preference among individual caterpillars.

As the only choice for a wingless caterpillar seems to be whether to feed on or to leave an encountered plant, we examined whether the caterpillars refuseed to feed on T. kanzawai-infested leaves. We introduced a fifth-instar T. oldenlandiae caterpillar onto a detached $C$. japonica compound leaf infested by three $T$. 
kanzawai females. This test was conducted only for T. oldenlandiae (18

replications using six caterpillars). We then observed whether the caterpillars fed on or left the leaves.

\section{Coincidental IGP on oligophagous mites: citrus red mites preyed upon by swallowtail caterpillars}

\section{Behavioral avoidance of $P$. citri against $P$. xuthus feeding}

To observe the behavioral responses of $P$. citri when attacked by $P$. xuthus caterpillars, we collected $P$. trifoliata leaves infested by $P$. citri. These leaves were presented to a fifth-instar $P$. xuthus and we observed coincidental IGP on $P$. citri individuals in the same manner described above. The data for the active stages were subjected to a chi-square test.

\section{Preference of $P$. xuthus caterpillars for $P$. citri-infested leaflets}

To determine whether $P$. xuthus caterpillars avoided feeding on $P$. citri-infested leaves, we removed the center leaflet of a detached $P$. trifoliata compound leaf and confined two mated female $P$. citri onto one of the leaflets in the manner described above (Fig. 2-a). After 24 h, we introduced a fifth instar P. xuthus caterpillar (19 replicates using five caterpillars) and observed which leaflet the caterpillars targeted first (Fig. 2-b). The data were subjected to a Wilcoxon signed-ranks test.

To examine whether the caterpillars refused to feed on $P$. citri-infested leaves, a fifth-instar $P$. xuthus caterpillar was introduced onto a detached $P$. trifoliata compound leaf infested by two $P$. citri females (19 replications using five caterpillars). We then observed whether the caterpillars fed on or left the leaves. 


\section{Results}

\section{Coincidental IGP on polyphagous mites: Kanzawa spider mites preyed upon by hornworms}

\section{Behavioral avoidance of T. kanzawai against hornworm feeding}

All eggs and quiescent mites were consumed together with $C$. japonica leaves by hornworms (Fig. 3). The proportions of consumed mites did not differ between mite strains, but did among the developmental stages of the mite (Table. 1). Although nearly all mites in the active stages tried to escape attack, mature mites were less likely to be consumed (Fig. 3). Some female adult mites escaped from infested leaves via petioles or by traveling over the body surface of the hornworms.

\section{Preference of hornworms for T. kanzawai-infested leaflets}

Neither hornworm species distinguished leaflets infested by T. kanzawai from uninfested ones (Fig. 4a, b). No tested hornworms (out of 29 trials for $T$. oldenlandiae and 24 trials for T. japonica) refused to feed on the provided leaves, and all leaves were eventually fully consumed. Moreover, when provided only with infested leaves, no tested T. oldenlandiae caterpillars (out of 18 trials) refused to feed on the leaves, suggesting that the caterpillar does not refuse spider mite-infested leaves as a rule.

\section{Coincidental IGP on oligophagous mites: citrus red mites preyed upon by swallowtail caterpillars}

\section{Behavioral avoidance of $P$. citri against $P$. xuthus feeding}

All eggs and quiescent mites were consumed together by a $P$. xuthus caterpillar with $P$. trifoliata leaves (Fig. 5). The proportions of consumed active mites differed significantly among mite stages, indicating that mature mites are less likely to be consumed ( $\chi^{2}=18.72, P<0.001$; Fig. 5). 


\section{Preference of $P$. xuthus for $P$. citri-infested leaflets}

Papilio xuthus caterpillars did not distinguish between leaflets infested by $P$. citri and uninfested ones (Fig. 4c). No tested P. xuthus caterpillars (out of 19 trials) refused to feed on provided leaves, and all leaves were eventually consumed. Moreover, when provided only with infested leaves, only one tested $P$. xuthus caterpillars (out of 23 trials) refused to feed on the leaves, suggesting that the caterpillar does not refuse spider mite-infested leaves as a rule.

\section{Discussion}

All tested caterpillar species consumed the spider mites together with the host plant leaves. Since the degree of spider mite infestation on the leaves was similar to that in the wild (Shirotsuka, personal observation), any coincidental IGP observed between herbivores could also be expected under natural conditions. There are some examples of IGP on spider mites by omnivores that feed on both herbivores and their host plants (Trichilo and Leigh, 1986; Pallini et al., 1997; Agrawal and Klein, 2000; Magalhães et al., 2005). According to the terminology proposed by Polis et al. (1989), this is the first report of coincidental IGP on spider mites by herbivores that exclusively feed on plants. We predict that such coincidental IGP should be universal between giant grazers and spider mites given that we observed two examples from the two interactions examined. Such overlooked interactions could explain, at least in part, the unknown mortality of spiders and other small herbivores in the wild.

All of the T. kanzawai individuals as well as some $P$. citri in active stages tried to escape coincidental IGP. Although ambulate migration of some spider mites is triggered by predator-associated odors (Magalhães et al., 2002), ambulate escaping of $T$. kanzawai and $P$. citri may have been triggered by physical stimuli rather than odor-based stimuli because the mites only showed escaping behavior after being attacked by the caterpillars. Even when T. kanzawai can successfully escape from caterpillar attack, it will incur a fitness cost of losing all relatives in the quiescent stages along with their shelter (webs). Therefore, any trait of $T$. kanzawai that helps it to avoid hornworm attack would be been favored. However, neither hornworm species avoided feeding on T. kanzawai-infested leaves, suggesting that the mite-infested leaves do not discourage caterpillar feeding. Despite serious damage to T. kanzawai populations on $C$. japonica caused by 
hornworms, it may be an evolutionarily rare event for the mite, which feeds on hundreds of host plant species (e.g., Gomi and Gotoh 1996). Otherwise, as some plant species systemically induce chemical defenses in response to spider mite infestation (Karban and Carey, 1984), the mites may have systemically altered the quality of both infested and uninfested leaflets.

Given the results of these experiments, we hypothesized that an oligophagous mite $P$. citri that shares citrus host plants with swallowtails in time and space would have developed effective avoidance mechanisms against the intraguild predator. However, more $P$. citri individuals appeared to be consumed by caterpillars compared to T. kanzawai, although the proportions of consumed mites cannot be directly compared given the differences among intraguild predator species. Unexpectedly, several active stage $P$. citri individuals did not move, even when under attack by the caterpillar. This characteristic appears maladaptive unless it has overwhelming benefits under other conditions, such as against predators other than swallowtail caterpillars. This remains to be examined in future studies.

Like T. kanzawai, P. citri exhibited no adaptations for avoiding coincidental IGP by swallowtail caterpillars other than escaping. Since spider mites have developed a variety of predator avoidance tactics against predatory mites (Grostal and Dicke 1999; Pallini et al. 1999, 2000; Oku et al. 2003), coincidental IGP by randomly feeding giant caterpillars is likely less important compared to predation by the predatory mites that directly search for the prey spider mites (e.g., Hoy and Smilanick 1981; Sabelis and Van de Baan 1983). In addition, since the caterpillars always consume plant leaves irrespective of spider mite infestation, the caterpillars would not benefit the shared prey (plants), unlike the case of IGP among predators, which seems to often benefit shared prey (herbivores), depending on the conditions (Janssen et al. 2007).

\section{Acknowledgements}

We thank two anonymous reviewers for helpful comments. We also thank members of the Laboratory of Ecological Information for valuable suggestions and encouragement. This work was supported by the Japan Society for the Promotion of Science [Basis Research C; grant number 21580066 to S. Y.]. 


\section{References}

Agrawal, A. A. and Klein, C. N. (2000) What omnivores eat: direct effects of induced plant resistance on herbivores and indirect consequences for diet selection by omnivores. J. Anim. Ecol. 69: 525-535

Faraji F., Janssen A., Van Rijin P. C. J. and Sabelis M. W. (2000) Kin recognition by the predatory mite Iphiseius degenerans: discrimination among own, conspecific, and heterospecific eggs. Ecol. Entomol. 25: 147-155.

Fukuda, H., Hama, E., Kuzuya, T., Takahashi, A., Takahashi, M., Tanaka, B., Wakabayashi, M. and Watanabe, Y. (1982) The life histories of butterflies in Japan. Vol. 1. Hoikusha Publishing Co., Ltd., Osaka. pp. 101-105

Gomi, K. and Gotoh, T. (1996) Host plant preference and genetic compatibility of the Kanzawa spider mite, Tetracychus kanzawai Kishida (Acari: Tetranychidae). Appl. Entomol. Zool. 31: 417425

Grostal P. and Dicke M. (1999) Direct and indirect cues of predator risk influence behavior and reproduction of prey: a case for acarine interactions. Behav. Ecol. 10: 422-427

Holt R. D. and Polis G. A. (1997) A theoretical framework for intraguild predation. Am. Nat. 149: 745-764

Hoy, M. A. and Smilanick J. M. (1981) Non-random prey location by the phytoseiid predator Metaseiulus occidentalis: differential responses to several spider mite species. Entomol. Exp. Appl. 29: 241-253

Janssen, A., Sabellis, M. W., Magalhães S., Montserrat, M. and Van der Hammen, T. (2007) Habitat structure affects intraguild predation. Ecology 88: 2713-2719

Janzen, D. (1977) Why fruits rot, seeds mold, and meet spoils. Am. Nat. 111:691-713

Kaneko, S. (2007) Predator and parasitoid attacking ant-attended aphids: effects of predator presence and attending ant species on emerging parasitoid numbers. Ecol Res 22:451-458

Karban, R.and Carey J. R. (1984) Induced resistance of cotton seedlings to mites. Science 225:5354

Langellotto, G. A., Rosenheim, J. A. And Williams, M. R. (2006) Assessing trophic interactions in a guild of primary parasitoids and facultative hyperparasitoids: stable isotope analysis. Oecologia. 150: 291-299

Magalhães S., Janssen A, Hanna R. and Sabelis M. W. (2002) Flexible antipredator behaviour in herbivorous mites through vertical migration in a plant. Oceologia. 132: 143-149

Magalhães, S., Janssen, A., Montserrat, M. and Sabelis, M. W. (2005) Host-plant species modifies the diet of an omnivore feeding on three trophic levels. Oikos 111: 47-56

Makino T. (1982) Rhamnales Vitaceae. In: Honda, M. (ed.) Makino's illustrate of flora in colour. Hokuryukan Co., Ltd., Tokyo. pp.322

Montserrat M., Magalhães S., Sabelis M. W., De Roos A. M. and Janssen A. (2008) Patterns of exclusion in an intraguild predator-prey system depend on initial conditions. J Anim. Ecol. 77: $624-630$ 
Mutuura, A., Yamamoto, Y. and Hattori, I. (1965) Sphingidae. In: Early stages of Japanese moths in colour vol. 1. (Revised by Isshiki, S.) Hoikusha Publishing Co., Ltd., Osaka. pp.26-28 Oku, K. and Yano, S. (2007) Spider mites (Acari: Tetranychidae) deform their host plant leaves: aninvestigation from the view point of predator avoidance. Entomol. Soc. Am. 100: 69-72 Oku, K., Yano, S. and Takafuji, A. (2003) The use of a refuge during the quiescent stage spider mites in the presence of a predator. Entomol. Exp. Appl. 108: 71-74

Ozawa, M. and Yano, S. (2009) Pearl bodies of Cayratia japonica (Thumb.) Gagnep. (Vitaceae) as alternative food for a predatory mite Euseius sojaensis (Ehara) (Acari: Phytoseiidae). Ecol Res 24:257-262

Pallini, A., Janssen, A. and Sabelis, M. W. (1997) Odour-mediated responses of phytophagous mites to conspecific and heterospecific competitors. Oecologia 110: 179-185

Pallini A., Janssen A. and Sabelis M. W. (1998) Predators induce interspecific herbivore competition for food in refuse space. Ecol. Lett. 1:171-177

Pallini A., Janssen A. and Sabelis M. W. (1999) Spider mites avoid plants with predators. Exp. Appl. Acarol. 23:803-815

Polis G. A., Myers C. A. and Holt R. D. (1989) The ecology and evolution of intraguild predation: potential competitors that eat each other. Annu. Rev. Ecol. Syst. 20: 297-330

Roda A., Nyrop J., ECnglish-Loeb G. and Dicke, M. (2001) Leaf pubescence and two-spotted spider mite webbing influence phytoseiid behavior and population density. Oecologia 129: 551560

Sabelis M. W. and Van de Baan H. E. (1983) Location of distant spider mite colonies by Phytoseiid predators: demonstration of specific kairomones emitted by Tetranychus urticae and Panonychus ulmi. Entomol. Exp. Appl. 33:303-314

SAS Institute Inc. (1998) SAS/STAT user's guide, release 6.03 edition. SAS Institute, Cary. Satake, Y., Ohwi, J. Kitamura, S., Watari, S. and Tominari, T. (1982) Wild flowers of Japan. Herbaceous plants (including Dwarf Subshrubs). Heibonsha Ltd., Tokyo. p.238

Satake, Y., Hara, H., Watari, S. and Tominari, T. (1989) Wild flowers of Japan. Woody plants. Heibonsha Ltd., Tokyo. p.282

Shinkaji, N. (1979) Geographical distribution of the citrus red mite, Panonychus citri and European red mite, P. ulmi in Japan. In; Recent Advances in Acarology, vol. 1 (J. G. Rodriguez, ed.). Academic Press, New York, pp. 81-87

Strong D. R., Lawton J. H. and Southwood T. R. E. (1984) Insect on Plants. Blackwell Scientific Publications, Oxford.

Trichilo, P. J. and Leigh, T. F. (1986) Predation on spider mite eggs by the Western Flower Thrips, Frankliniella occidentalis (Thysanoptera: Thripidae), an opportunist in a cotton agroecosystem. Environ. Entomol. 15: 821-825

Fig. 1-a Preparation for a choice test using C. japonica leaflets. Leaflets with broken lines were removed before the experiment. The petiole of leaflet in a pair was banded with wet cotton to prevent T. kanzawai from escaping, while the other leaflet served as a control

Fig. 1-b Experimental setup for a choice test using hornworms. We removed wet cotton from the petiole and introduced a hornworm at the bottom edge of the $C$. japonica compound leaf 
Fig. 2-a Preparation for a choice test using $P$. trifoliata leaflets. Leaflets with broken lines were removed before the experiment. The petiole of one leaflet in a pair was banded with wet cotton to prevent $P$. citri from escaping, while the other leaflet served as a control

Fig. 2-b Experimental setup for the choice test using a swallowtail caterpillar. The wet cotton was removed from the petiole and the caterpillar was introduced at the bottom edge of the P. trifoliata compound leaf

Fig. 3 Proportion of T. kanzawai consumed when attacked by a hornworm

Fig. 4 Preference of caterpillars for mite-infested vs. uninfested leaflets (a: NS; $P=0.36$, b: NS; $P$ $>0.99$, c: NS; $P=0.22$ )

Fig. 5 Proportion of $P$. citri consumed when attacked by a $P$. xuthus caterpillar

Table 1 Results of the Wald test for the effects of populations and developmental stages on the survival of T. kanzawai when attacked by a hornworm 
Fig. 1

a)

T. Kanzawai females

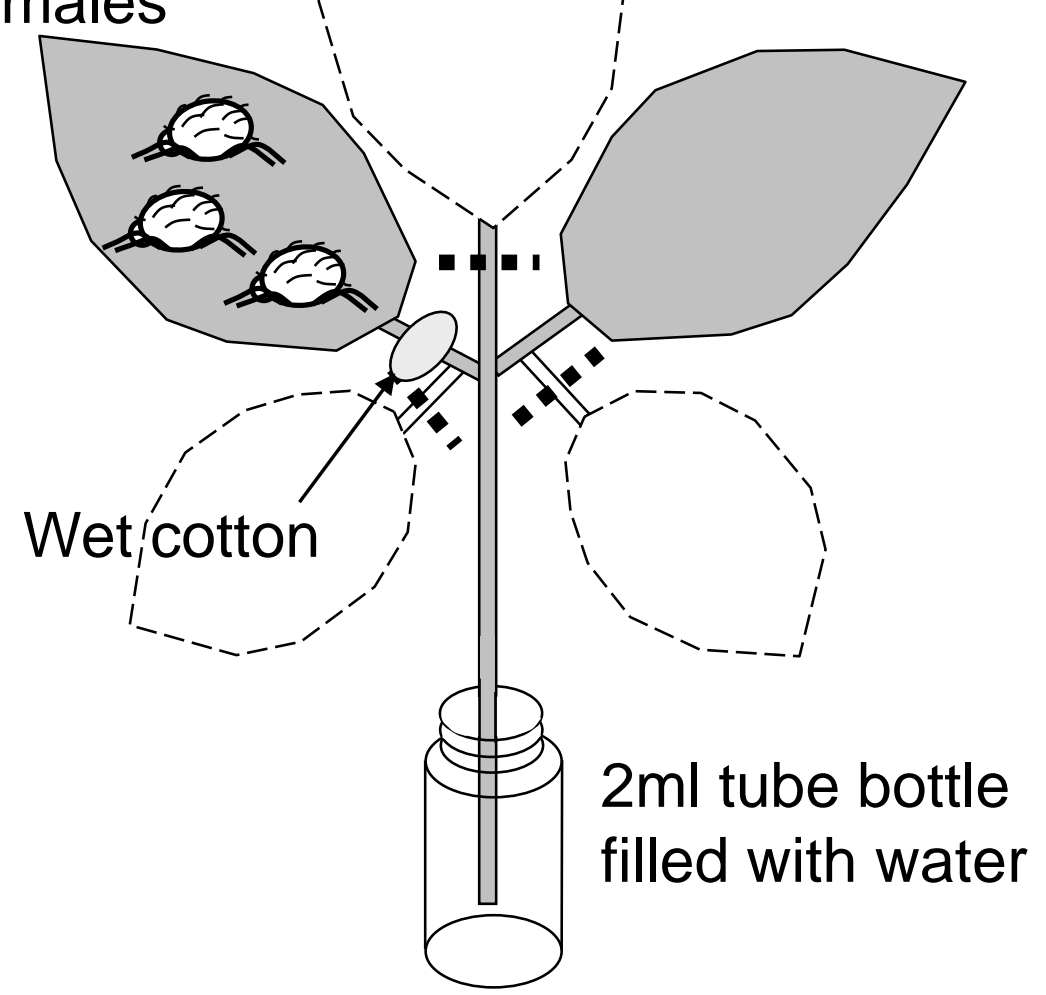

b)

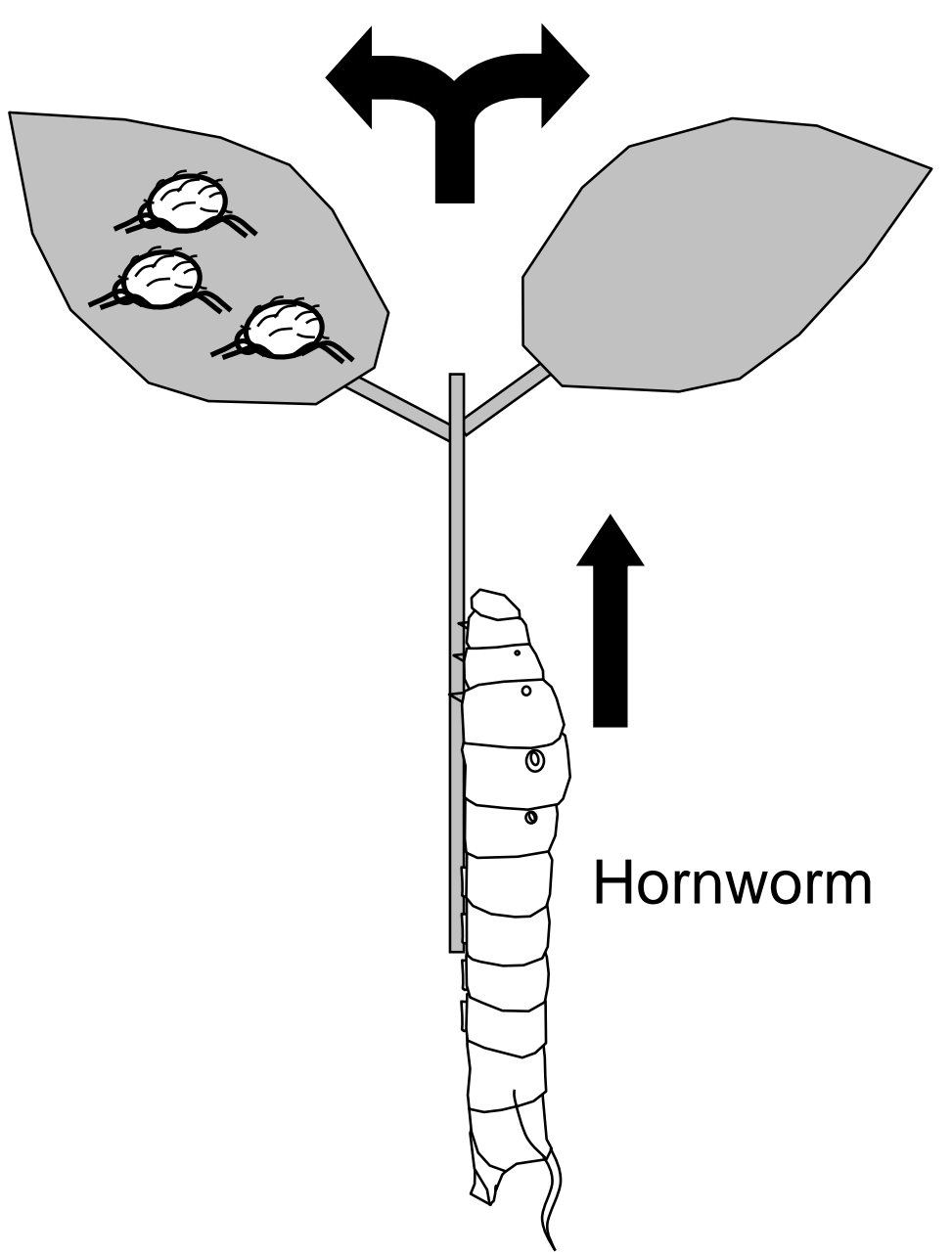


Fig. 2
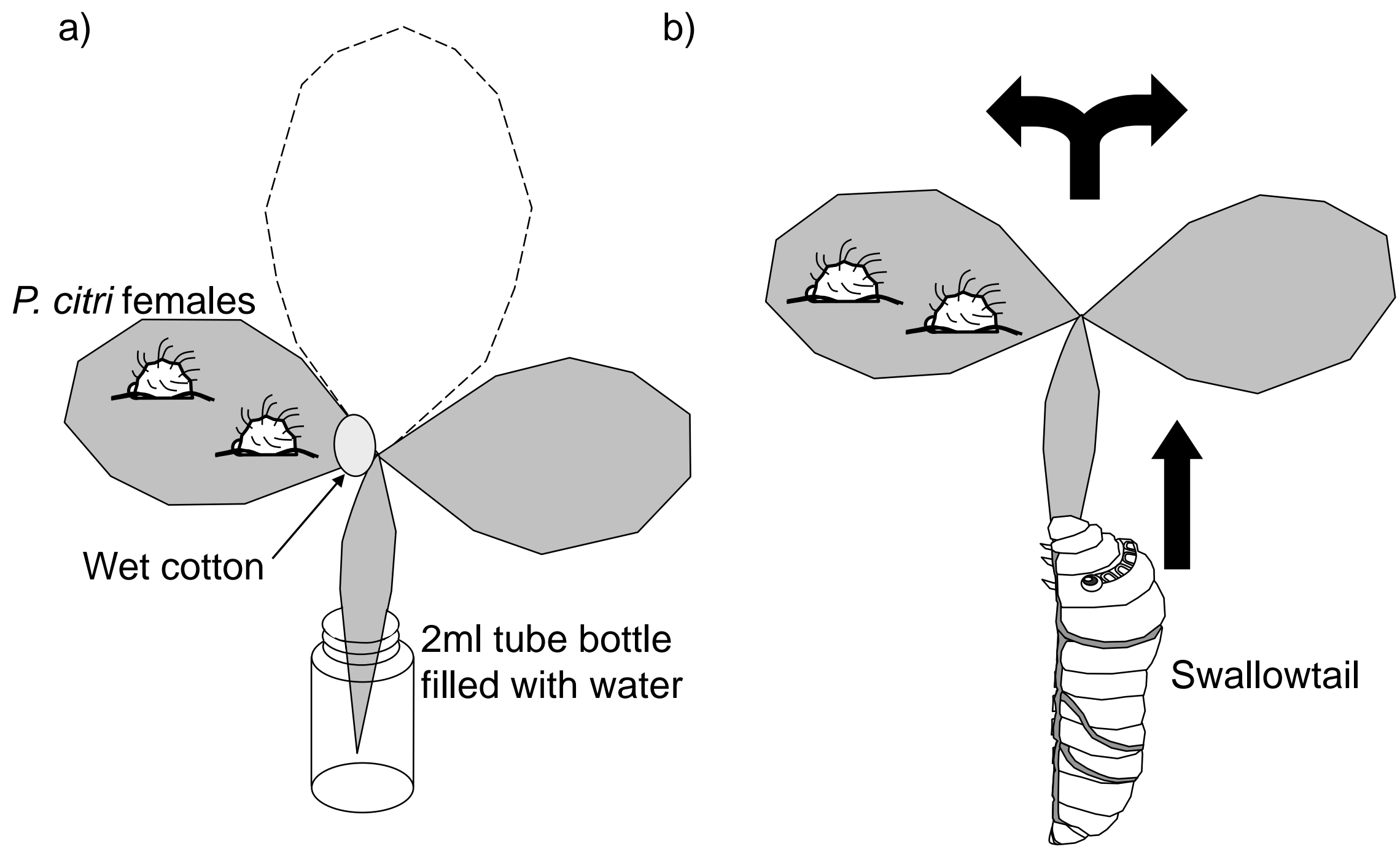
Fig. 3

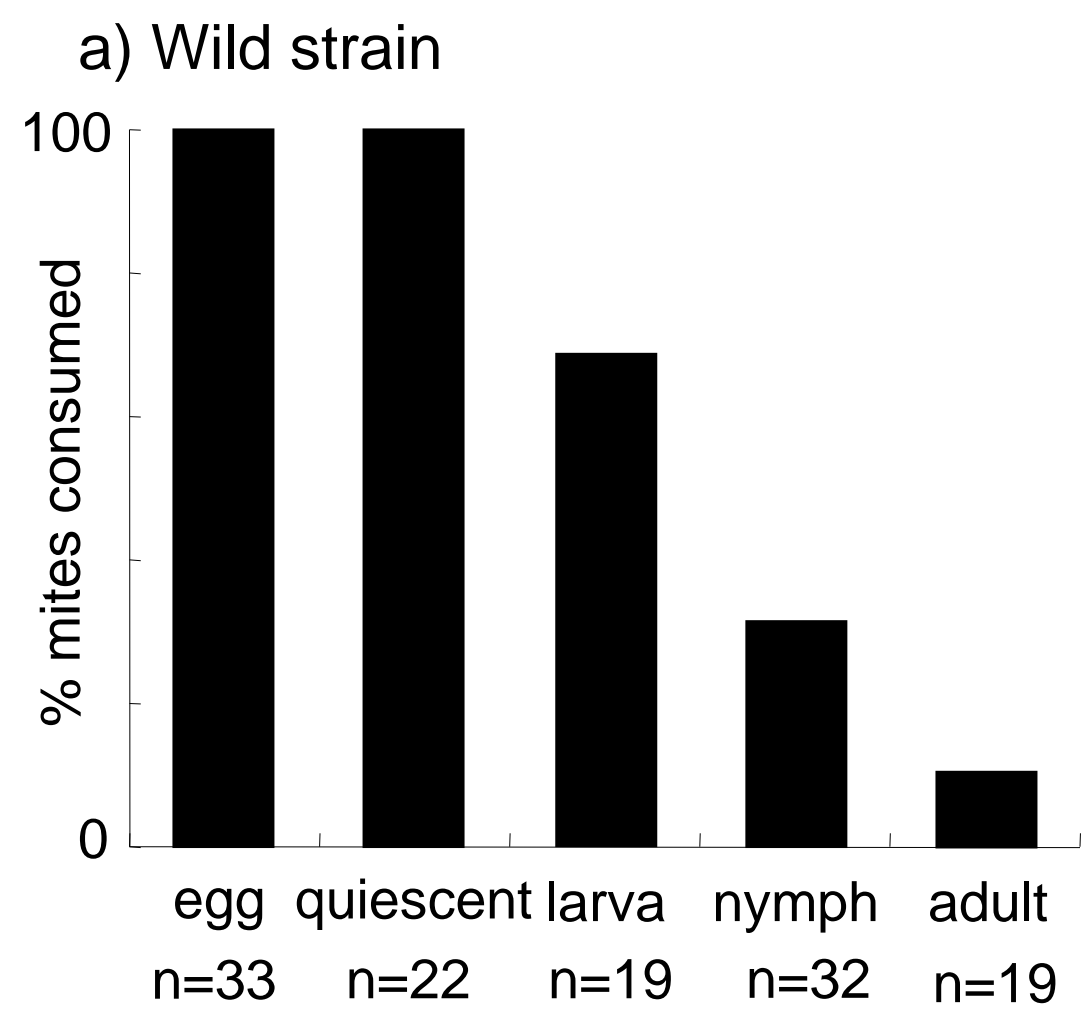

b) Laboratory strain

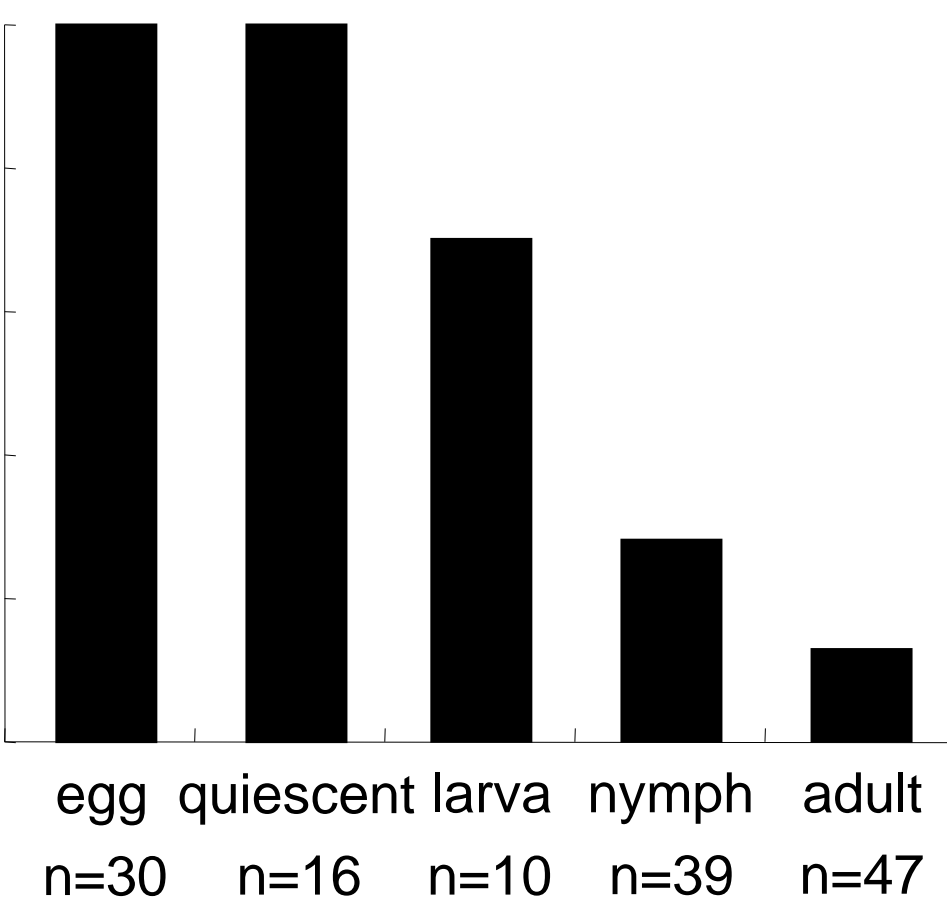


mite

a) T. oldenlandiae C. japonica T. kanzawai

b) T. japonica

C. japonica

T. kanzawai
c) P. xuthus
P. trifoliata
P. citri

18

11

13

11

12

7

50 
Fig. 5

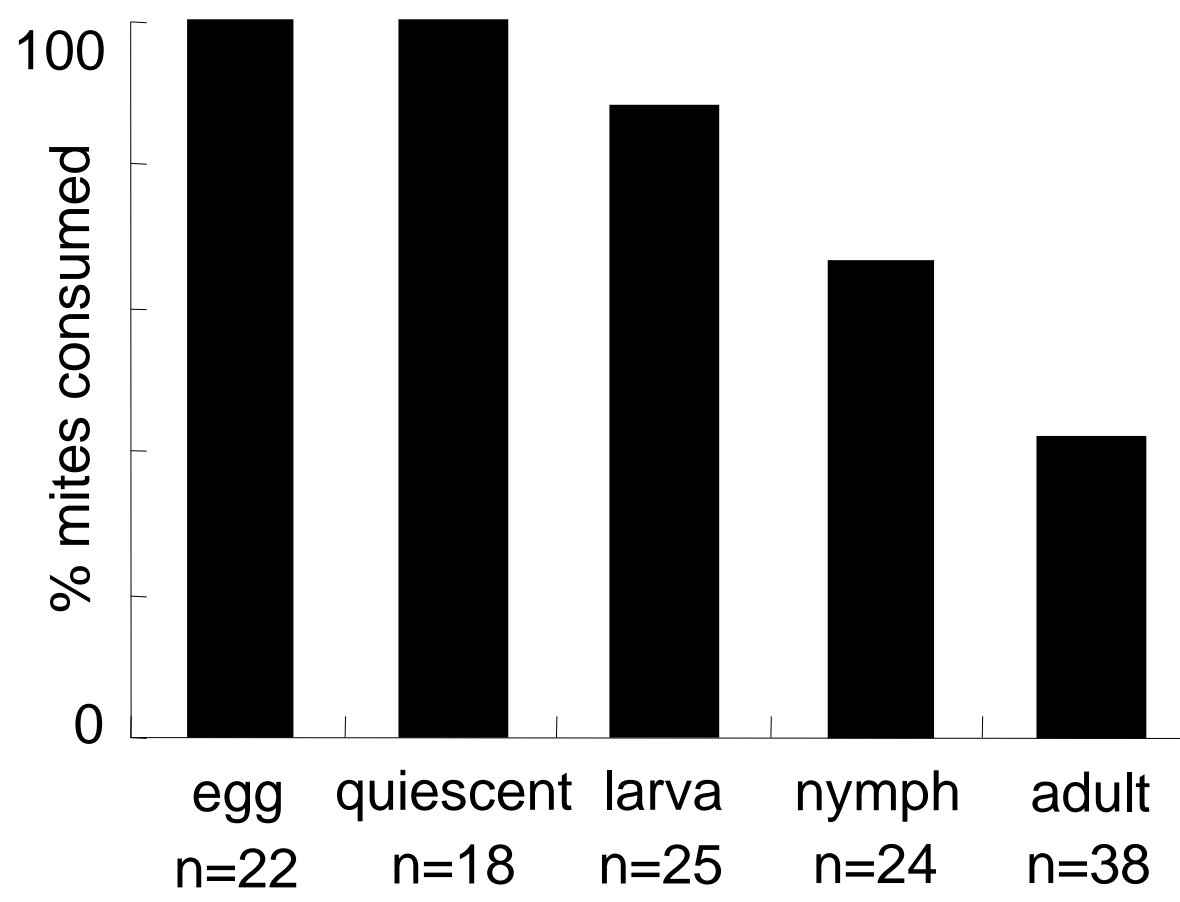




\begin{tabular}{llll}
\hline Factor & df & Wald $\chi^{2}$ & $P$ \\
\hline Population (Wild/ Laboratory) & 1 & 0.0035 & 0.9531 \\
Stage (larva/ nymph/ adult) & 2 & 22.592 & $P<0.001$ \\
Population $\times$ stage & 2 & 0.2171 & 0.8971 \\
\hline
\end{tabular}

